\title{
Risk Attitude towards Mandatory Retirement Protection in Hong Kong: Why Are Risky Investments More Attractive?
}

\author{
Ricky S. Wong ${ }^{1}$ \\ ${ }^{1}$ Department of Supply Chain Management, Hang Seng Management College, Hong Kong \\ Correspondence: Ricky S. Wong, Room D631, Hang Seng Management College, Hang Shin Link, Siu Lek Yuen, \\ Shatin, N.T., Hong Kong. Tel: 85-2396-3458. E-mail: rickywong@hsmc.edu.hk
}

Received: January 16, 2014 Accepted: January 26, 2014 Online Published: February 26, 2014

doi:10.5539/ass.v10n6p205 URL: http://dx.doi.org/10.5539/ass.v10n6p205

\begin{abstract}
The government of Hong Kong Special Administrative Region (HKSAR) launched the Mandatory Provident Fund (MPF) scheme as a major source of retirement protection. Now, over 2.6 million employees and self-employed persons are currently making contribution to this scheme and they are required to decide on allocation of their MPF contributions to different MPF choices. However, we know little about how their decisions are formed. One major contribution of this study is to investigate people's perceptions of MPF and their preferences of MPF choices. And, this study has adopted the predictions of prospect theory, in order to explain why risky choices are more attractive to the public. Findings indicated that more individuals perceived MPF contribution as a loss, than those who perceived it as a gain; those who perceived MPF as a loss generally made higher contributions to the risky fund.
\end{abstract}

Keywords: prospect theory, risk-seeking, mandatory provident fund, mandatory retirement protection

\section{Introduction}

The current research focuses on how people in Hong Kong make decisions in their mandatory retirement investment. Although the mandatory retirement protection scheme has been implemented for more than 10 years, little study has been conducted to investigate how people's decisions are formed. In light of the Lehmann Brothers' mini-bonds incident and HK\$20.23 billion worth of Lehmann Brothers' structured products sold to over 43700 Hong Kong investors (Legislative Council of the Hong Kong Special Administrative Region, 2012), more rigorous regulation of financial products and a fuller understanding of people's investment preferences may come to fore. It is expected the consequences could be more disastrous in the domain of mandatory retirement protection, since it serves as a long-term investment and determines the quality of people's living standards upon retirement. It is therefore important to consider how people make decisions in their retirement protection investment.

This study was designed to contribute to the domain of MPF investment in Hong Kong, by explaining why risky fund type is more popular to MPF contributors (i.e. mostly employees and self-employed persons). As will be discussed later, MPF contributors appear to be willing to "gamble" their long-term retirement savings on risky financial products.

\subsection{The Development of MPF in Hong Kong}

The Hong Kong Special Administrative Region (HKSAR) government considered the implementation of Mandatory Provident Fund (MPF) scheme in 1995 (Puidak, 1995). Along with the governments of other developed countries, the establishment of the MPF scheme was driven by the expectation that the percentage of people aged 65 or above would increase from 13 percent to 30 percent in 2041 (Yu, 2008). The MPF System was launched in December 2000 and was designed to be a retirement protection. All employees and self-employed persons, aged between 18 and 65, are covered by the MPF scheme. Employer and employee are required to contribute to the MPF scheme monthly with an amount of \$1,250 HK dollars (USD \$160 approximately) or a $5 \%$ of the monthly salary (whichever is lower) (Mandatory Provident Fund Schemes Authority [MPFSA], 2001, 2011, 2013).

The MPF scheme has grown rapidly in its economic value. Until March 2013, a total net asset amount of $\$ 455.33$ billion Hong Kong dollars (\$58.3 billion USD) was contributed to the MPF System (MPFSA, 2013). 
About $84 \%$ of the total labour population (or about 2.60 million individuals) is now covered under MPF schemes (MPFSA, 2013). As of 2013, the largest four MPF providers are the Hong Kong and Shanghai Banking (HSBC) Provident Trustee (Hong Kong) Limited, AIA Company (Trustee) Limited, BOCI-Prudential Trustee Limited and Manulife Provident Funds Trust Company (Gadbury, 2013). Regardless of the choice of MPF provider, MPF contributors need to choose between the type(s) of funds offered by the MPF provider. Subsequently, they make decisions on the distribution of their monthly savings. Suppose that four different funds (Funds A, B, C and D) are available from which employees may choose. Employees need to assign a percentage of their savings to each of these funds (i.e. between $0 \%$ and $100 \%$ ); their monthly contributions will accordingly be spent on their fund choices. For example, one may decide to invest $50 \%$ of his or her MPF contributions (as well as the employer's) to Fund B and $50 \%$ to Fund C.

Although the MPF market is growing rapidly, we know very little about the rationale behind contributors' decisions. A fuller understanding of decision makers' behaviour and choice would be useful. The fund types available to contributors usually differ in terms of their risk levels, ranging from low risk to high risk funds. The most risky MPF type is equity fund. By far, equity fund has attracted a large amount of contributions from the public. As of June 2013, the net asset value of equity funds is $\$ 165510$ million (HKD) and the number of approved equity funds in the market is 171 (comprised of about $36 \%$ of different MPF types) (MPFSA, 2013). Equity funds are expected to be able to generate higher potential returns but are associated with higher risks. It begs a question: Why are MPF contributors attracted to risky investment when it comes to their retirement protection? In other words, it raises a question as to why people are willing to take a high level of risk when it comes to their retirement savings. This study argues that an assumption that most MPF contributors perceive their MPF contributions as gain entails a significant loss of generality.

The purpose of this research is twofold. First, I seek to explore why risky MPF is more popular and has attracted more contributions in relation to less risky funds. Second, I examine whether MPF contributors differ in terms of how they perceive MPF as a mandatory retirement protection. This research attempts to use the well-documented descriptive model of decision making-Prospect Theory that considers people's risk attitudes in gain and loss domains-in the context of MPF contribution. In particular, the results from this study serve to explain the risk-seeking behaviour of MPF contributors in Hong Kong.

\section{Literature Review and Development of Hypotheses}

The first research question addressed in the current research is: Do MPF contributors perceive mandatory retirement protection differently? It is speculated that people may see their MPF contributions as a source of gain or loss. Here I will consider how employees' perceptions of MPF are formed. The following focuses on how MPF may be perceived as a gain or loss dependent on what they believe they could have achieved without the government mandatory retirement protection scheme.

One place to begin is that MPF contributors perceive MPF as a long-term saving, which is consistent with the intention of HKSAR government. This is particular true if employees would have spent the amount of MPF contributions (i.e. $\$ 2500$ for each month including employers' contribution) without the mandatory retirement protection scheme. Consequently, MPF contributors see that they will receive a lump sum of their investment when they retire at the age of 65 .

MPF contributors, on the other hand, may perceive their MPF investment as a potential loss. This is true especially if contributors believe that they would have better invested their mandatory contribution by themselves than the performance of available MPF types in the market. This conjecture is based on the assumption that contributors would have received more monetary returns in the long run. Owing to this isomorphism, this study sets out to explore the possibility that MPF contribution could be a source of gain or loss, depending on the perspective of contributors.

\subsection{Difference in Risk Attitudes in Gain and Loss Domain}

A large body of research on decision making has shown that people's risk attitudes tend to be different when facing gains and losses. Kahneman and Tversky (1979) developed a theory of choice-prospect theory. The main element of prospect theory is an S-shaped utility function. Its shape is concave (risk-averse) in the domain of gains and is convex (risk-seeking) in the domain of losses (Kahneman \& Tversky, 1979; Tversky \& Kahneman, 1983, 1992). To illustrate the element of prospect theory, an example would be helpful. Consider the following hypothetical problems with two different choices.

Problem A:

Choice $1-50 \%$ to win $\$ 1000,50 \%$ chance to win nothing; Choice 2-a sure gain of $\$ 500$; 
Problem B:

Choice $1-50 \%$ to lose $\$ 1000,50 \%$ chance to lose nothing; Choice 2-a sure loss of $\$ 500$;

When being placed in the gain domain (Problem A), most people would opt for Choice 2 over Choice 1 . That is, people are generally risk-averse, and a risk-less choice is preferred. In the loss domain (Problem B), the gamble (Choice 1) appears to be more attractive to most people than a sure loss (Choice 2). They are more willing to take the risk so as to avoid losses.

People's decisions that follow the prediction of prospect theory can be found in real-life situations. Studies suggested that being risk-seeking in the loss domain can explain why investors tend to hold on to their losing stock (Grinblatt \& Han, 2005; Shefrin \& Statman, 1985). Apart from investment, the findings of prospect theory were also used to explain and predict consumers' choices and household budgeting (Thaler, 1985, 2008).

To generalise and extend the predictions of prospect theory, it may be that MPF contributors, who perceive MPF as a gain, are more attracted to low-risk funds and those, who see MPF as a potential loss, tend to be more risk-seeking, thus making a higher contribution to risky MPF choice. As discussed, risky funds tend to be more popular by the public; therefore, a better understanding of contributors' perceptions and their investment behaviour would help explain this phenomenon. The current study employed a MPF simulation experiment and tested the following hypotheses:

Hypothesis 1: The percentage of MPF contributors who perceive MPF as a loss is greater than the percentage of those who perceive it as a gain.

Hypothesis 2: Individuals, who perceive MPF as a loss, allocate a higher percent to the high-risk fund than those who perceive it as a gain.

\section{Method}

To increase external validity, this experiment adopted the four major MPF types that most MPF providers offer. It is possible that subjects interpret different funds differently, and their interpretations are likely to be influenced by the past memory or experience. To rule out this possibility, the relative risk levels of different funds were indicated so that how subjects perceive the relative risk levels would be more consistent. An index from 1 to 5 was adopted whereby 1 presented lowest risk investment option and 5 was the highest risk fund. A similar index has been used by the financial institutions in Hong Kong (American International Assurance Company (Trustee) Limited, 2012).

\subsection{Participants}

A stratified sampling method was adopted to recruit participants from different industries. Subjects were invited via e-mails or telephone calls. The experiment was conducted in Hang Seng Management College or the company in which subjects were working after office hours. Subjects working in various industries (e.g. banking, accounting, management, engineering, marketing, trading, etc.) were selected from the labour population in Hong Kong and they were making MPF contributions at the time of their participation. This sample, therefore, reflects the norms of a random sample of MPF contributors in Hong Kong. One hundred and two subjects participated in what was described as a "MPF allotment task". Participants took part in the study voluntarily. The sample included 57 men and 45 women, with ages ranging from 20 to 53 years and a mean of $27.71(S D=8.34)$ years.

\subsection{Procedures}

All participants received the general information that described the MPF allocation task on a paper handout before the exercise began (see Appendix A for details). The experimenter provided subjects with specific instructions, details about mandatory provident fund types, the corresponding risk index of funds, and a short quiz to ensure that subjects understood the relative risk levels of different fund types available. The instructions, information, and quiz were given on paper. The experimenter checked answers to every question; subjects in error were told to attempt the question again. Most subjects were correct on their first attempt; all were correct on their second attempts. Subjects were given thirty minutes to complete the MPF allocation task and the perception questionnaire. Subjects' perceptions towards MPF were tested individually after the fund allocation experiment, because the effect of measurement of perceptions on subjects' allocation to MPF (if any) could be minimized.

The pre-task questionnaire included a number of demographic questions and the post-task questionnaire elicited participants' perceptions towards MPF. After participants completed the experiment, they were debriefed about the purpose of the experiment. 


\subsection{MPF Allocation Task}

The simulation used in this study was an allocation task of individuals' mandatory contributions to MPF. The situation required individuals to decide upon the type(s) and corresponding percent(s) of each MPF type that they would invest. There were four MPF types for participants to choose from. They were different in terms of their nature and corresponding risk level (see Appendix B for details).

Due to the fact that the HKSAR government requires the MPF providers to offer at least one capital preservation fund, this experiment included a "Fixed income fund" to strengthen the external validity of this study. There were four MPF types for participants to choose and decide on how much they would invest their MPF contributions. They were different in terms of their nature and corresponding risk level. Other fund types included in this study are commonly offered by the MPF providers in Hong Kong (see, American Insurance Assurance Company (Trustee) Limited, for example).

\subsection{Manipulation Check}

To ensure that the perceived risk levels of MPF types worked as intended, a short quiz was given to subjects before the beginning of the experiment. Subjects were asked "Which of the funds is the most risky investment that may give you the highest return?" and "Which of the funds shown is the relatively least risky option for you?" $96 \%$ of subjects gave the correct answers in their first attempt, and the remaining $4 \%$ answered correctly in the second attempt.

\subsection{Measures}

To assess whether participants perceive MPF as a gain or loss, I asked them to state the extent of their agreement with two statements. Statements 1 and 2 were: "I perceive MPF contribution as a loss because I believe that I can achieve higher financial gains by investing myself than by MPF contribution." and "I personally consider $M P F$ contribution as a gain in future (i.e. a large lump sum of saving for retirement)". They responded on a 7-point Likert scale ( 1 = "strongly disagree", 7 = "strongly agree").

In the MPF task, subjects were asked to indicate which fund(s) and the corresponding percent(s) that they would invest. The percentage was computed for each subject. If the total assignment to funds was not equal to $100 \%$, the subject was asked to make corresponding changes. This dependent measure was the percentages invested in the Equity fund (the highest risk fund type).

\section{Results}

One-sample $t$-tests were performed to examine subjects' perceptions of MPF. If Hypothesis 1 is correct, a larger proportion of subjects will tend to agree with loss statement and a smaller proportion of subjects will tend to disagree with the gain statement. As a result, the mean responses to Statement 1 (Statement 2) would be higher (lower) than "4" in the 7-point Likert scale (i.e. neutral category). The findings lend support to this hypothesis. Subjects generally tended to agree with Statement $1(M=5.06, t=6.21, p<.0005)$. In contrast, they indicated that they tended to disagree with Statement $2(M=3.53, t=-2.78, p<.005)$.

A linear regression analysis was conducted to test the association between contribution to equity fund and perception of MPF. I regressed the percentage of monthly MPF contribution allocated to the high-risk MPF, on responses to Statement 1 , subjects' age and gender. It was found that there was a positive relationship between responses to Statement 1 and allocation to high-risk MPF, $B=3.51(S E=1.62, t=2.17, p<.05)$ and the regression coefficients for age and gender were insignificant $\left(S E_{\text {age }}=0.325\right.$, n. s., $S E_{\text {gender }}=5.41, \mathrm{n}$. s. $)$. Including age and gender in the model ruled out the possibility that perceiving MPF as a loss was due to subjects' gender or age.

\section{Discussion}

This research considers Hong Kong employees' perceptions towards the MPF scheme. The pattern of subjects' contributions to the risky fund, as demonstrated in the MPF allocation experiment, is consistent with what MPF contributors prefer in real-life situations. Overall, subjects contributed $41 \%$ to the equity fund, compared to only $27 \%$ of the low-risk fund (i.e. Fixed Income Fund). The study also extends Kahneman and Tversky's (1979) Prospect Theory to involve allocation of one's own resources in Hong Kong-people's decision on MPF investment. In line with the hypotheses, the findings show that a larger percentage of contributors consider MPF contribution as a loss rather than a gain (long-term saving). Some contributors indicated that their own choice of investment is likely to outperform the MPF, and consequently, mandatory retirement contribution would be considered as a loss of potential financial returns. Notably, the results are consonant with studies showing that in a loss quadrant, individuals tend to be risk-seeking (Gonzalez, Dana, Koshino, \& Just, 2005; Tversky \& 
Kahneman, 1981, 1986). Specifically, it was found that when controlling for age and gender, MPF contributors, who perceived MPF as a loss, generally allocated higher levels of their contributions to equity fund than those who perceived MPF as a gain. This provides us with insights into why MPF contributors are more attracted to risky options.

One might argue that mature contributors may be more risk-averse, especially those who are closer to their retirement age. This is because contributors who are closer to their retirement age (e.g. 65) are expected to perceive MPF as a retirement saving, resulting in higher levels of MPF investment in risk-free options. The current findings suggest that the relationship between perceptions towards MPF and risk-seeking behaviour holds true when controlling for age and gender. Nonetheless, it is premature to conclude that young and mature MPF contributors always follow the prediction of prospect theory in mandatory retirement protection. A limitation of this study is that although the sample included participants in different age groups, over $80 \%$ of participants were less than 40 years of age. More research is necessary to fully test the relationship between age and perception of MPF as a gain or loss for the aged contributors who will retire in the next few years.

The current study also has important practical implications to the HKSAR government in the area of MPF education. Although the MPF scheme has resulted in more employment opportunities in the banking industry (Chan, 2003), the government should not underestimate the importance of educating contributors how to make unbiased decisions. The large percentage of contributors, who believe that their own investment plans would outperform MPF fund, may root in overconfidence. Overconfidence is a well-documented cognitive bias and has been examined in different disciplines such as bargaining and finance (Benoit \& Dubra, 2011; Caputo, 2013; Gervais \& Heaton, 2011). Considering the intention of MPF that it provides retirement protection to the public, it is highly important for the under-privileged employees to be aware of the potential risks of their MPF choices, since they will heavily rely on the MPF during their retirement.

This research moves the field forward by opening several avenues to explore. Future studies should investigate the potential framing effects of MPF. Studies have demonstrated that whether something is a gain or loss is measured relative to a reference point (Tversky \& Kahneman, 1981, 1986). That is, reference point may be shifted and as a result, individuals' risk attitudes may change significantly (Gonzalez et al., 2005; Larraza-Kintana, Gomez-Mejia, \& Wiseman, 2011; Levin, Gaeth, Schreiber, \& Lauriola, 2002; Seo, Goldfarb, \& Barrett, 2010; Tversky \& Kahneman, 1981, 1986). Specifically, Tversky and Kahneman (1981) have shown that the reference point can also be shifted by a mere labeling of outcomes. Another study that considers investors' decisions in stock market shows that for returns below target, a large majority of individuals appear to be risk seeking and for returns above target, a large majority appear to be risk averse (Fiegenbaum \& Thomas, 1988). It is uncertain as to whether people's decisions may differ as a function of how MPF is being framed by a third party. It begs another question: What are the impacts on contributors' decisions if MPF providers frame their products as gain or loss?

Finally, it is important to note that the findings from this study are confined to mandatory retirement investment. People do not necessarily perceive retirement protection as a loss in other countries where contributions are not mandatory. For example, UK citizens, who contribute to Individual Savings Account (ISA), may not share the same view and behave differently. In the UK, ISA serves as a saving and investment scheme that provides tax relief to UK residents, and the contribution is not mandatory. They may choose investment options involving different levels of risk such as cash ISA and stock ISA cash (HM Revenue \& Customs, 2013). Since ISA works on a voluntary basis, it is plausible that UK employees or residents do not perceive their ISA investment as a potential loss, because they will not choose to invest in ISA if they expect that they receive better financial returns from other financial products.

In conclusion, I have demonstrated that people in Hong Kong may perceive the mandatory retirement protection scheme as a gain or loss. An explanation of why risky MPF is more popular has been given. Also, the guidelines provided by the HKSAR government focus primarily on the administrative charges of MPF providers (MPFSA, 2011), and the results from this study demonstrate the importance of addressing the potential cognitive biases that contributors may suffer in the context of MPF.

\section{Acknowledgements}

I thank Jonathan Lam for his help in data collection. I also appreciate the feedback from the editor and reviewers of Asian Social Science. 


\section{References}

American International Assurance Company (Trustee) Limited. (2012). Mandatory provident fund choices. Retrieved from https://www.aia-pt.com.hk/MPF/en/fund/choices/

Benoit, J., \& Dubra, J. (2011). Apparent overconfidence. Econometrical, 79, 1591-1625. http://dx.doi.org/10.3982/ECTA8583

Caputo, A. (2013). A literature review of cognitive biases in negotiation process. International Journal of Conflict Management, 24, 374-398. http://dx.doi.org/10.1108/IJCMA-08-2012-0064

Chan, K. C. (2003). Protecting the ageing poor or strengthening the market economy: The case of the Hong Kong Mandatory Provident Fund. International Journal of Social Welfare, 12, 123-131. http://dx.doi.org/10.1111/1468-2397.00250

Fiegenbaum, A., \& Thomas, H. (1988). Attitudes toward risk and the risk-return paradox: Prospect theory explanations. Academy of Management, 31, 85-106. http://dx.doi.org/10.2307/256499

Gadbury, J. (2013). MPF market share report. Retrieved from http://www.thempfblog.com/choosing-mpf-fund-needed/

Gervais, S. J. B., \& Heaton, T. O. (2011). Overconfidence, compensation contracts, and capital budgeting. The Journal of Finance, 66, 1735-1777. http://dx.doi.org/10.1111/j.1540-6261.2011.01686.x

Gonzalez, C., Dana, J., Koshino, H., \& Just, M. (2005). The framing effect and risky decisions: Examining cognitive functions with fMRI. Journal of Economic Psychology, 26, 1-20. http://dx.doi.org/10.1016/j.joep.2004.08.004

Grinblatt, M., \& Han, B. (2005). Prospect theory, mental accounting, and momentum. Journal of Financial Economics, 78, 311-339. http://dx.doi.org/10.1016/j.jfineco.2004.10.006

HM Revenue \& Customs. (2013). Individual savings account (ISA) statistics. Retrieved from http://www.hmrc.gov.uk/statistics/isas/statistics.pdf

Kahneman, D., \& Tversky, A. (1979). Prospect Theory: An analysis of decision under risk. Econometrical, 47, 263-292. http://dx.doi.org/10.2307/1914185

Larraza-Kintana, M., Gomez-Mejia, L. R., \& Wiseman, R. M. (2011). Compensation framing and the risk-taking behavior of the CEO: Testing the influence of alternative reference points. Management Research: The Journal of the Iberoamerican Academy of Management, 9, 32-55.

Legislative Council of the Hong Kong Special Administrative Region. (2012). Report of the subcommittee to study issues arising from Lehmann Brothers-related minibonds and structured financial products. Retrieved from http://www.legco.gov.hk/yr08-09/english/hc/sub_com/hs01/report/hs01_rpt.htm

Levin, I. P., Gaeth, G. J., Schreiber, J., \& Lauriola, M. (2002). A new look at framing effect: Distribution of effect sizes, individual differences, and independence of types of effects. Organizational Behavior and Human Decision Processes, 88, 411-429. http://dx.doi.org/10.1006/obhd.2001.2983

Mandatory Provident Fund Schemes Authority. (2001). Mandatory provident fund schemes statistical digest. Retrieved from http://www.mpfa.org.hk/eng/information_centre/statistics/mpf_schemes_statistical_digest/files/Mar_2001_ SD.pdf; http://dx.doi.org/10.1006/obhd.2001.2983

Mandatory Provident Fund Schemes Authority. (2011). A 10-year performance review of the MPF system. Retrieved from http://www.mpfa.org.hk/eng/information_centre/publications/research_reports/files/10_year_performance_ English.pdf

Mandatory Provident Fund Schemes Authority. (2013). Mandatory provident fund schemes statistical digest. Retrieved

from http://www.mpfa.org.hk/eng/information_centre/statistics/mpf_schemes_statistical_digest/index.jsp

Puidak, P. (1995). Hong Kong passes mandatory provident fund law. Social Security Bulletin, 58(4), 139-140.

Seo, M., Goldfarb, B., \& Barrett, L. F. (2010). Affect and the framing effect within individuals over time: Risk taking in a dynamic investment simulation. Academy of Management, 53, 411-431. http://dx.doi.org/10.5465/AMJ.2010.49389383

Shefrin, H., \& Statman, M. (1985). The disposition to sell winners too early and ride losers too long: Theory and 
evidence. The Journal of Finance, 40, 777-790. http://dx.doi.org/10.1111/j.1540-6261.1985.tb05002.x

Thaler, R. H. (1985). Mental accounting and consumer choice. Marketing Science, 4, 199-214. http://dx.doi.org/10.1287/mksc.4.3.199

Thaler, R. H. (2008). Mental accounting and consumer choice. Marketing Science, 27, 15-25. http://dx.doi.org/10.1287/mksc. 1070.0330

Tversky, A., \& Kahneman, D. (1981). The framing of decisions and the psychology of choice. Science, 211, 453-458. http://dx.doi.org/10.1126/science.7455683

Tversky, A., \& Kahneman, D. (1983). Extensional versus intuitive reasoning: The conjunction fallacy in probability judgment. Psychological Review, 90, 293-315. http://dx.doi.org/10.1037/0033-295X.90.4.293

Tversky, A., \& Kahneman, D. (1986). Rational choice and the framing of decisions. The Journal of Business, 59, 251-278. http://dx.doi.org/10.1086/296365

Tversky, A., \& Kahneman, D. (1992). Advances in prospect theory: Cumulative representation of uncertainty. Journal of Risk and Uncertainty, 5, 297-323. http://dx.doi.org/10.1007/BF00122574

Yu, S. W. (2008). Pension reforms in Hong Kong: Using residual and collaborative strategies to deal with the government's financial responsibility in providing retirement protection. Journal of Aging and Social Policy, 20, 493-510. http://dx.doi.org/10.1080/08959420802191704

\section{Appendix A}

\section{General Information}

All subjects read the following:

"Imagine that you have recently changed to a new Mandatory Provident Fund provider. You need to show the provider which particular fund(s) you are interested in. Please assign a percent(s) to the fund(s) indicated in the table below. The percentage may vary between $0 \%$ and $100 \%$. A $100 \%$ in one particular fund indicates that you invest all your MPF contribution to this fund whereas a $0 \%$ represents that you decide not to invest any of your savings in the fund. The second column shows you the relative risk or return rating $(1=$ lowest risk, $5=$ highest risk). Note that your answer(s) must be presented in percentage and in a multiple of 5\%."

\section{Appendix B}

Table 1. Resource allocation task

\begin{tabular}{lll}
\hline Constituent Fund & $\begin{array}{l}\text { Risk Rating (1-5) Low risk (1) } \\
\text { High risk (5) }\end{array}$ & $\begin{array}{l}\text { MPF Contribution in Percent (in } \\
\text { a multiple of 5\%) }\end{array}$ \\
\hline Lifestyle Funds & 3 & \\
Equity Funds & 5 & \\
Fixed Income Funds & 1 & \\
Dynamic Asset Allocation Fund & 4 & $\mathbf{1 0 0 \%}$ \\
\hline
\end{tabular}

\section{Copyrights}

Copyright for this article is retained by the author(s), with first publication rights granted to the journal.

This is an open-access article distributed under the terms and conditions of the Creative Commons Attribution license (http://creativecommons.org/licenses/by/3.0/). 